Delft University of Technology

\title{
Chloride Ingress of Carbonated Blast Furnace Slag Cement Mortars
}

\author{
Holthuizen, Patrick; Copuroglu, Oguzhan; Polder, Rob
}

DOI

10.1007/978-3-319-59471-2_10

Publication date

2018

Document Version

Final published version

Published in

High Tech Concrete: Where Technology and Engineering Meet

\section{Citation (APA)}

Holthuizen, P., Copuroglu, O., \& Polder, R. (2018). Chloride Ingress of Carbonated Blast Furnace Slag Cement Mortars. In D. Hordijk, \& M. Lukovic (Eds.), High Tech Concrete: Where Technology and Engineering Meet: Proceedings of the 2017 fib Symposium, held in Maastricht, The Netherlands, June 12-14, 2017 (pp. 73-82) https://doi.org/10.1007/978-3-319-59471-2_10

Important note

To cite this publication, please use the final published version (if applicable).

Please check the document version above.

\section{Copyright}

Other than for strictly personal use, it is not permitted to download, forward or distribute the text or part of it, without the consent of the author(s) and/or copyright holder(s), unless the work is under an open content license such as Creative Commons.

Takedown policy

Please contact us and provide details if you believe this document breaches copyrights.

We will remove access to the work immediately and investigate your claim. 
Green Open Access added to TU Delft Institutional Repository

'You share, we take care!' - Taverne project

https://www.openaccess.nl/en/you-share-we-take-care

Otherwise as indicated in the copyright section: the publisher is the copyright holder of this work and the author uses the Dutch legislation to make this work public. 


\title{
Chloride Ingress of Carbonated Blast Furnace Slag Cement Mortars
}

\author{
Patrick E. Holthuizen ${ }^{1,2(\bowtie)}$, Oğuzhan Çopuroğlu ${ }^{1}$, \\ and Rob B. Polder ${ }^{1,3}$ \\ ${ }^{1}$ Department of Materials and Environment, Faculty of Civil Engineering \\ and Geosciences, Delft University of Technology, Stevinweg 1, \\ $2628 \mathrm{CN}$ Delft, The Netherlands \\ P.E.Holthuizen@tudelft.nl \\ 2 Department of Material Technology and Inspection, BAM Infraconsult bv, \\ H.J. Nederhorststraat 1, P.O. Box 268, 2800 AG Gouda, The Netherlands \\ 3 Department Structural Reliability, TNO Technical Sciences, \\ P.O. Box 49, 2600 AA Delft, The Netherlands
}

\begin{abstract}
In the Netherlands civil engineering structures, such as overpasses, bridges and tunnels are generally built using blast furnace slag cement (BFSC, CEM III/B) concrete, because of its high resistance against chloride penetration. Although the Dutch experience regarding durability performance of BFSC concrete has been remarkably good, its resistance to carbonation is known to be sensitive, especially when the used slag percentage is high. In a field investigation on a highway overpass damage was found in sheltered elements such as abutments and intermediate supports, which was attributed to chloride induced corrosion enhanced by carbonation that occurred prior to the chloride exposure.

Many structures built using BFSC could be prone to this mechanism, i.e. carbonation enhanced chloride induced corrosion, negatively affecting their durability. Focus of the research was given on the influence of carbonation on the chloride penetration resistance of BFSC mortars with varying slag content. In light of the characteristics from the overpass case, it was assumed that first there is a period of carbonation during sheltered exposure, and subsequently joint leakage causes exposure to chlorides. In order to identify the influence of slag content on carbonation, chloride penetration resistance and their coupled effect, mortars with twelve cement blends in a range of $0-70 \%$ slag were evaluated based on chloride migration coefficient, accelerated carbonation and electrical resistivity.

This study shows that carbonation of BFSC mortars increases the porosity, consequently decreasing the chloride penetration resistance. Binders with $50 \%$ or more slag were found to have a significantly lower resistance after carbonation. Consequently, the chloride penetration resistance of a given concrete cover strongly depends on the duration of carbonation and the resulting carbonation depth, hence influencing its lifespan. The service life was estimated using a simplified model for the chloride penetration time of a combined carbonated and uncarbonated layer. It was found that mortar with a slag content between 35 and $50 \%$ that was carbonated before chloride exposure show the lowest influence of carbonation on the chloride penetration resistance.
\end{abstract}


Keywords: Blast furnace slag cement $\cdot$ Carbonation $\cdot$ Chloride ingress · Durability $\cdot$ RCM-test

\section{Introduction}

For concrete structures exposed to aggressive environments, durability is a major concern (Bertolini et al. 2013). Due to ageing of the existing stock, increasing numbers of civil engineering structures develop corrosion related damage (Polder et al. 2012). Similar case was studied in this research, the overpass at Hattemerbroek. Modern Design, Build, Maintain and Finance (DCMF) contracts enforce contractors to be financially responsible for repair and maintenance over a contractual period of typically 30 years. Repairs are seen as an expensive necessity in order to satisfy the service life requirements, therefore service life prediction of existing structures is highly needed. One of the most frequently occurring durability issues is reinforcement corrosion, since abutments, girders, support beams and columns can be exposed to de-icing salt environments. Cracking and spalling of concrete cover and subsequent loss of steel cross section due to reinforcement corrosion can be initiated by chloride ingress or carbonation (Tuutti 1982).

Regulations such as (NEN-EN1992-1-1 2005), (NEN-EN 206-1 2000), deal with durability by selecting the governing Exposure Class and the corresponding minimum cover depth. The additional (ROK 1.2 2013)-guideline imposed by the Dutch government requires the use of BFSC cement with 50 to $80 \%$ slag, amongst others referring to chloride induced corrosion as the governing degradation mechanism. Generally, guidelines assume that in environmental conditions where chloride induced corrosion is important (XD), carbonation induced corrosion (XC) is less important and can be ignored.

From field measurements it can be seen that chloride penetration and carbonation can occur in parallel, which was the case for the overpass at Hattemerbroek. Bridge support elements are normally in sheltered conditions, which promote carbonation. During winter de-icing salts are used, which will dissolve and flow towards the joints. When joints start to leak after typically 15-25 years, due to any deformation, de-icing salts can come in contact with underlying carbonated concrete such as a support beam (see Fig. 1). Apparently there are concrete elements which are susceptible to degradation caused by multiple actions, for example a combined mechanism of carbonation and chloride ingress. This is not taken into account in the present regulations.

In The Netherlands civil engineering structures are mainly built using BFSC (CEM III/B), mainly due to long and good experience with such cements (Polder et al. 2014). The use of BFSC produces a high chloride penetration resistance (low diffusion), among others due to a fine pore structure. For structures in marine conditions (environmental classes XS), carbonation is very slow since the concrete is wet most of the time and therefore is less important (Polder and Rooij 2005). However for sheltered elements in XD environments carbonation can develop prior to any chloride exposure. It is known that carbonation leads to significant coarsening of the pore structure in slag-rich concrete which could influences the chloride diffusion resistance negatively (Copuroglu 2006). 
Therefore this research focuses on XD environmental conditions with chloride from de-icing salts. The main goal is to get a better understanding of degradation due to a combination of carbonation and chloride ingress in BFSC pastes and mortars as a function of slag content. Mortar with a range of slag contents is investigated to see (a) if there is a negative interaction between both degradation mechanisms and (b) what is the slag content that, under combined attack, would produce the longest Service Life. A simple two-layer model is set up for the combined effect of carbonation and

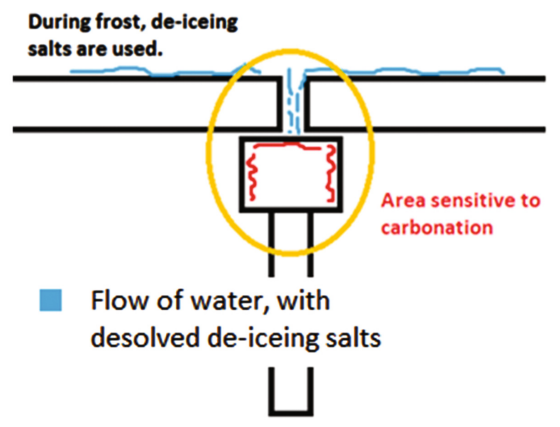

Fig. 1. Sketch of a leaking joint in which de-icing salts coming in contact with underlying carbonated concrete chloride ingress. After improvement (which was beyond the scope of the current study), such a model could be used to better design new structures for delay of corrosion due to this combined mechanism. The model can also be applied to existing structures to predict potential future damage. It was expected that there will be an optimal slag content with the highest chloride penetration resistance in carbonated and uncarbonated state. More details and additional results are reported in (Holthuizen 2016).

\section{Experimental Program}

In this research the influence of slag content was investigated on blended cements with slag contents in the range of $20-70 \%$ and a CEM I cement as reference. The range of slag contents was obtained by blending CEM I 42,5 N and CEM III/B 42,5 N in appropriate amounts and mixing for $3 \mathrm{~min}$ in a paint mixer. Light microscopy was used to qualitatively evaluate the degree of dispersion of the new cement blends. It was observed that the slag and clinker grains were not clustered and homogeneously dispersed therefore they were assumed to be sufficiently mixed.

As specimen type, cement mortars were preferred over concrete specimens for carbonation and chloride ingress testing, in order to assure a relatively homogeneous mixture and to limit uncertainty in the matrix. A w/c-ratio of 0.5 was used, in accordance with NEN-EN 206-1 for environmental class XC. The preparation of mortar was performed according to (NEN-EN-196-1 2005), using standard sand of $D_{\max }=2 \mathrm{~mm}$. Mortar specimens were cast as cylinders of $100 \mathrm{~mm}$ diameter and $50 \mathrm{~mm}$ length or $160 \times 40 \times 40 \mathrm{~mm}$ prisms. After one day curing in $\left(20 \pm^{\circ} \mathrm{C}\right.$, R.H. $\left.=55 \%\right)$ sealed moulds the specimens were demoulded and placed in a fog room $\left(20 \pm{ }^{\circ}\right.$ C, R.H. $\left.=95 \%\right)$.

At 28 days age the cylindrical specimens were first dried in ambient conditions for 4 days and then placed in the carbonation chamber at an age of 32 days. $\mathrm{CO}_{2}$-content was $3 \%$ to accelerate carbonation; the temperature was $20.0 \pm 1.0{ }^{\circ} \mathrm{C}$ and the $\mathrm{RH}$ c. $65 \%$. Specimens were exposed from all sides, using spacing brackets to regulate air circulation. The progress of carbonation was monitored on dummies using phenolphthalein as indicator. 
The electrical resistivity of carbonated and uncarbonated cylindrical and prismatic specimens was measured as an indication for their susceptibility to chloride penetration. Measurements on carbonated specimens were done after vacuum saturation in a calcium hydroxide solution prior to the RCM-test. In accordance with the RILEM TC-154 technical recommendation (Polder 2001) specimens were placed between two steel plates with moistened cloths and an alternating current with a frequency of $1000 \mathrm{~Hz}$ was applied. The resistivity $\rho$ [Ohm.m] was calculated by multiplying the measured resistance $R[\mathrm{Ohm}]$ with a geometrical constant, the contact area $A\left[\mathrm{~m}^{2}\right]$ divided by the thickness $L$ of the specimen [m].

Cylindrical specimens were tested for rapid chloride migration in accordance with (NT Build 492 1999). The specimens were placed in a catholyte, a solution of 10wt.\% $\mathrm{NaCl}$ in tap water. The voltage was adjusted depending on the initial current measured at a voltage of $30 \mathrm{~V}$. After the test duration the specimen is split axially and sprayed with a $0.1 \mathrm{M}$ silver nitrate solution, which produces a zone with white silver chloride precipitate after about $15 \mathrm{~min}$. The chloride penetration depth can be measured from the precipitation depth using a ruler and from this the chloride diffusion coefficient is calculated according to the equation given in NT Build 492.

\section{Results}

\subsection{Compressive Strength}

Approximately the same 28-day compressive strength was found for all blended cements with slag contents between 20 and $70 \%$ and for the reference CEM I mortar. Compressive strengths at 28 days exceeded $50 \mathrm{MPa}$ for all mixes, and flexural strengths varied from 6 to $8 \mathrm{MPa}$. Apparently the cement blends satisfy the expected strength level, based on the parent CEM I and CEM III/B 42.5 characteristics.

\subsection{Carbonation}

The carbonation depth was monitored for a period of 23 weeks for all mixtures while exposing to an elevated $\mathrm{CO}_{2}$ of 3 vol. \%; results of five cement blends are presented in Fig. 2. It should be noted that not all specimens were fully carbonated after 23 weeks, since a carbonation depth of 12.5 or $25 \mathrm{~mm}$ corresponds to a fully carbonated mortar specimen of respectively 25 or $50 \mathrm{~mm}$ thick. Some specimens contained an uncarbonated core, which is relevant for chloride migration testing (see below).

Using a simple square-root of time model, the carbonation rate can be expressed as a carbonation diffusion coefficient, $D_{\text {carb }}$. The $D_{\text {carb }}$ presented in Fig. 3 was determined using the carbonation depth after 23 weeks. A high diffusion coefficient indicates that $\mathrm{CO}_{2}$ penetrates the sample faster than materials with a low $D_{\text {carb }}$. Figure 3 shows higher $D_{\text {carb }}$ for higher slag contents, which is in contrast to their higher chloride penetration resistance (see below). This can be explained by their lower availability of 


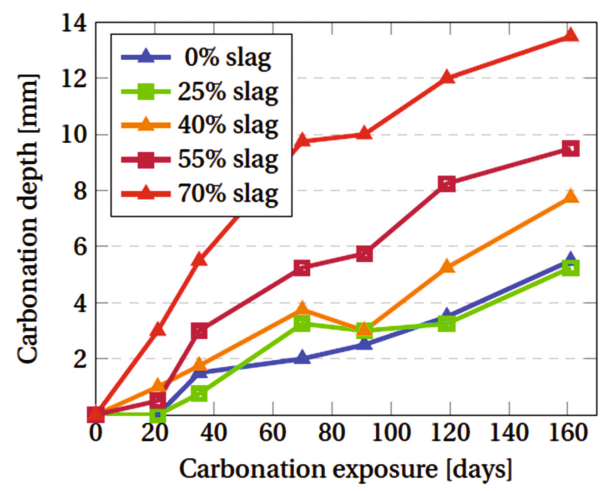

Fig. 2. Development of carbonation depth in $3 \% \mathrm{CO}_{2}$

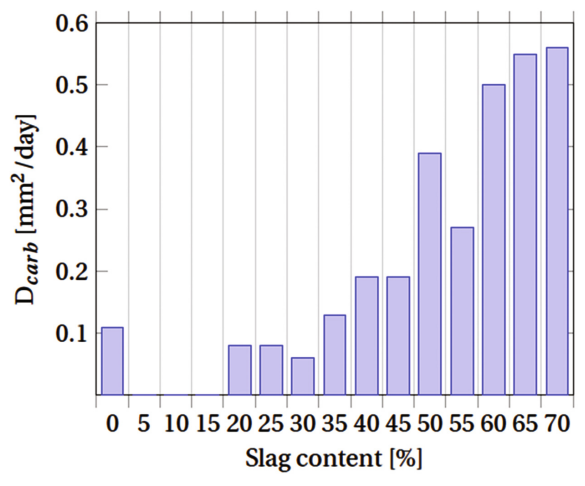

Fig. 3. Carbonation rate, $D_{\text {car }}$

calcium hydroxide in the material. Carbonation converts calcium hydroxide into calcite, which densifies the cement paste. Carbonation of cementitious matrix with a high slag content (which contain less calcium hydroxide) decomposes the C-S-H phase into porous $\mathrm{S}-\mathrm{H}$, leading an coarsened overall pore structure as portlandite content is not enough to compensate. As a result, a drastic change in the transport properties of carbonated slag-rich cementitious materials can be expected. Loss of C-S-H causes increased porosity and permeability and consequently changes the transport properties.

\subsection{Chloride Diffusion}

Uncarbonated specimens were tested with two different thicknesses, 25 and $50 \mathrm{~mm}$, and for two corresponding test durations, 6 and $24 \mathrm{~h}$, respectively. Chloride diffusion coefficients were calculated for both sizes and presented in Fig. 4. From the results it can be concluded that the calculated diffusion coefficient is similar for both thicknesses; and that a decaying trend with increasing slag content can be observed for uncarbonated material. With increasing slag content the chloride diffusion coefficient decreases from about 16.0 for CEM I to $2.0 \times 10^{-12} \mathrm{~m}^{2} / \mathrm{s}$ for CEM III/B (70\% slag). The resistivity for uncarbonated specimens follows a similar trend from low for $0 \%$ slag to high for $70 \%$ slag. Chloride diffusion and resistivity are related by an inverse relationship as reported in literature (Wegen et al. 2012).

However, the diffusion coefficient of higher slag content mortars changed drastically upon carbonation. After a period of 23 weeks in elevated $\mathrm{CO}_{2}$ of 3 vol. $\%$ the cylindrical mortar specimens were subjected to the RCM-test. From the chloride penetration after the chloride migration test on carbonated specimens it was observed that there are three types of chloride penetration profiles. For partly carbonated 


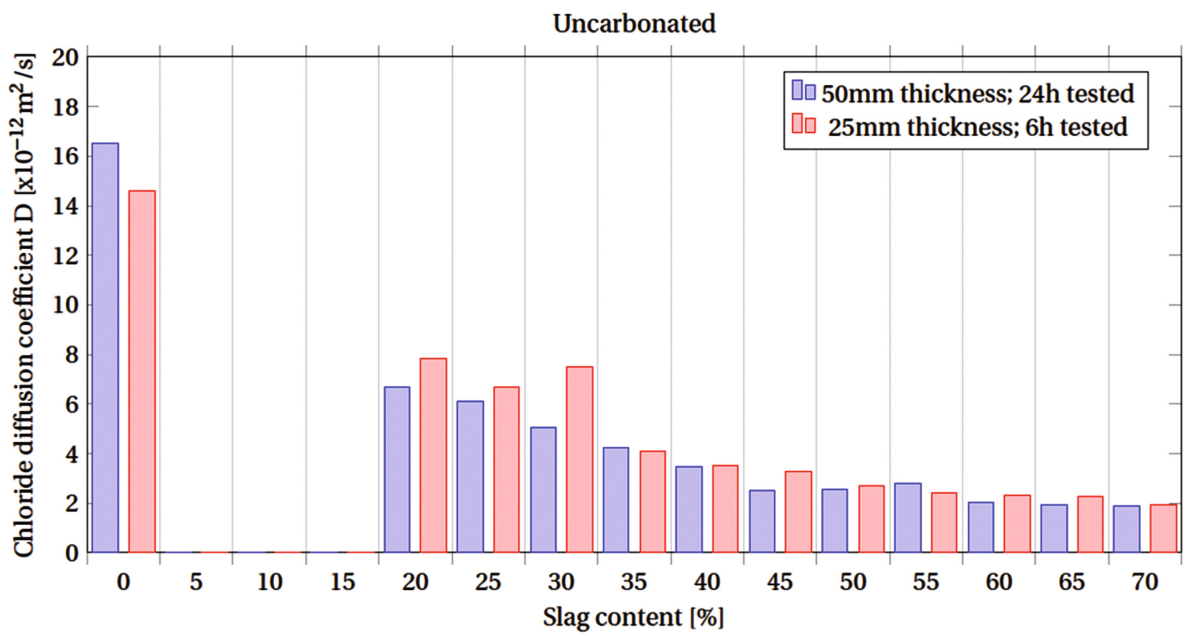

Fig. 4. Chloride diffusion coefficient of uncarbonated mortar specimens; w/c-ratio $0.5 ; 6$ months curing

specimens chloride ions penetrate into either the carbonated and uncarbonated areas or only the carbonated area. For fully carbonated samples, obviously the chloride only penetrates into carbonated material. In most cases the chloride penetration depth was less than the full specimen thickness and a migration coefficient could be calculated. However, for the $25 \mathrm{~mm}$ (fully) carbonated specimens with slag contents of 60, 65 and $70 \%$ it was found that chloride ions had penetrated through the entire specimen. Therefore it was not possible to measure the actual chloride penetration depth, consequently it was not possible to calculate the actual $D_{c l}$. The maximum chloride diffusion coefficient for a $25 \mathrm{~mm}$ thick mortar in a $6 \mathrm{~h} \mathrm{RCM-test} \mathrm{is} 29 \times 10^{-12} \mathrm{~m}^{2} / \mathrm{s}$; this is a lower limit as indicated in Fig. 5. If the values from slag contents of 45-55\% are linearly extrapolated a diffusion coefficient of $30-45 \times 10^{-12} \mathrm{~m}^{2} / \mathrm{s}$ could be found for slag contents of $60-70 \%$. It is concluded that carbonation of a $70 \%$ slag mortar will increase the chloride diffusion coefficient by 20 fold. The high chloride penetration resistance of uncarbonated BFSC-mortars is strongly reduced due to carbonation.

A similar trend was observed in the resistivity measurements. For uncarbonated specimens a linear increase in resistivity was observed with increasing slag content, corresponding to the decreasing chloride diffusion coefficient from Fig. 4. Resistivity measurements on carbonated specimens show an increase in resistivity up to slag contents of $45 \%$. For higher slag contents than $45 \%$ a decrease was observed for the electrical resistivity, matching the same pattern as was seen from the chloride diffusion tests. 


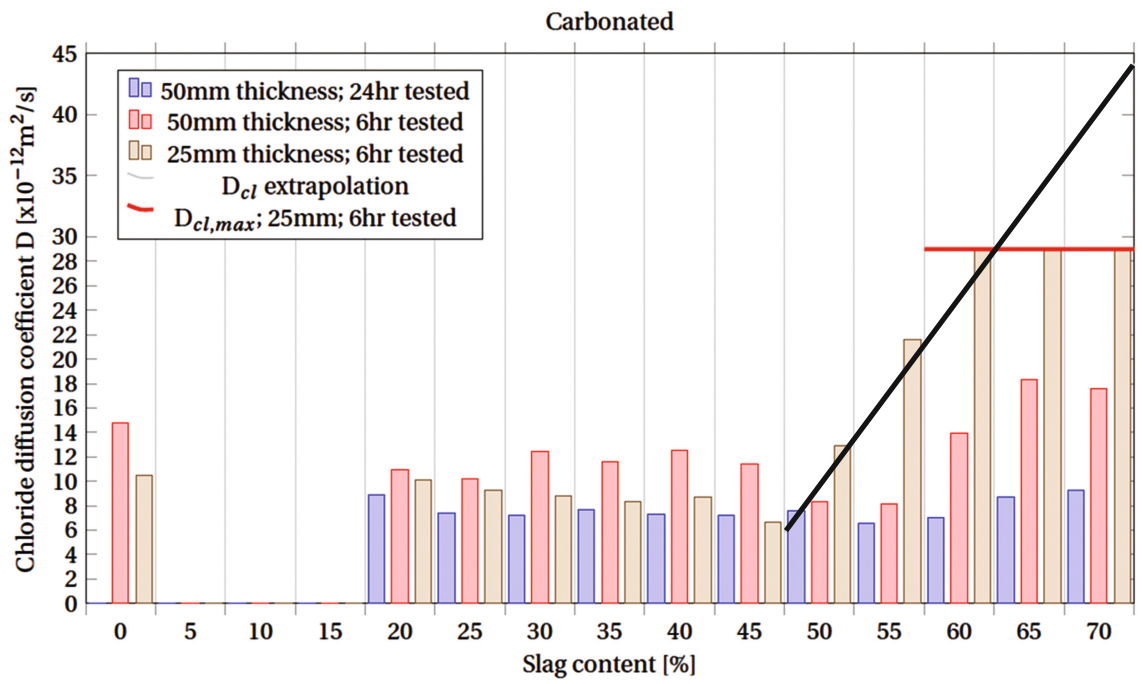

Fig. 5. Chloride diffusion coefficient after 6 months accelerated carbonation of mortar specimens $\left(3 \% \mathrm{CO}_{2}\right)$; w/c-ratio 0.5 ; $28 \mathrm{~d}$ curing; red line indicates lower limit for $60-70 \%$ slag related to full penetration; black line indicates extrapolation from $45-55 \%$ slag results

\section{Chloride Penetration Modelling}

Carbonation progress in ambient conditions was predicted based on the carbonation diffusion coefficients obtained by accelerated carbonation experiments on mortar specimens. Note that in further research this should be extended to concrete specimens. The chloride penetration time is dependent on the chloride diffusion resistance of two parts of a cover; a carbonated and an uncarbonated part.

If we consider uncarbonated conditions, Fig. 6a shows that the carbonation depth is zero for the slag contents tested. Therefore the chloride penetration can be solely considered as dependent on the diffusion properties of the uncarbonated material. The chloride penetration time is the time necessary to penetrate a mortar sample with a thickness of $50 \mathrm{~mm}$, which is shown in Fig. 6b. It can be seen that mortar with $70 \%$ slag requires the longest time for chlorides to penetrate the cover. It should be noted that the calculated chloride penetration time is not equal to the time-to-corrosion initiation, since the chloride threshold value at the reinforcement is left out of the scope.

A combined carbonation and chloride ingress scenario is based on the overpass at Hattemerbroek, a 40 year old structure with a high carbonation depth and deep chloride ingress. Assuming that sheltered elements were free to carbonate for 35 years before chloride exposure, the carbonation depth and resulting chloride penetration time were determined; results are presented in Fig. 7. The total chloride penetration time depends on the combined chloride penetration resistance of carbonated and uncarbonated matrix and their respective thicknesses. When the partly carbonated cover depth is subsequently exposed to chlorides, the chloride penetration time is 6 years for a slag content of $70 \%$ which is 15 years less than in uncarbonated material. It should be noted that for 


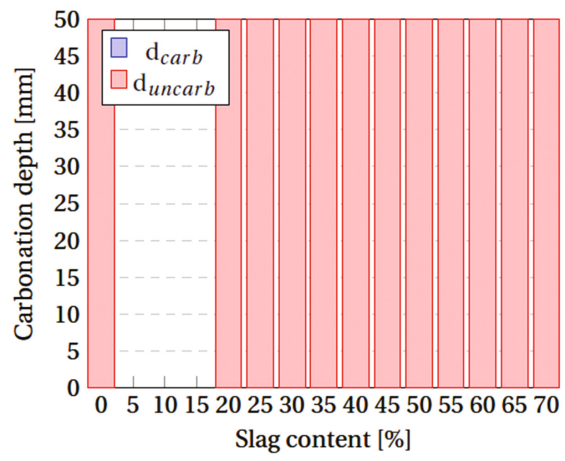

(a)

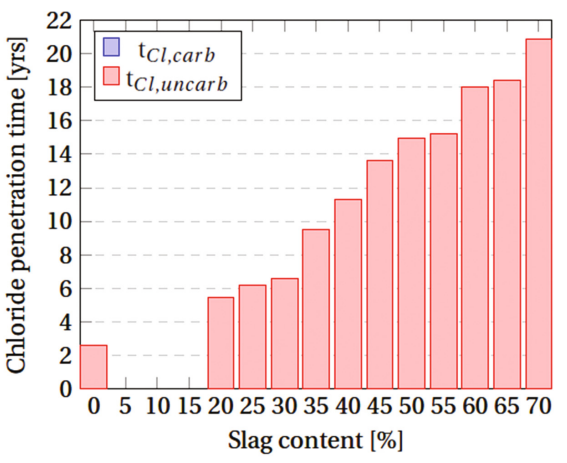

(b)

Fig. 6. No carbonation exposure prior to chloride exposure; (a) Zero carbonation depth; (b) Time needed for chloride ions to penetrate $50 \mathrm{~mm}$ cover

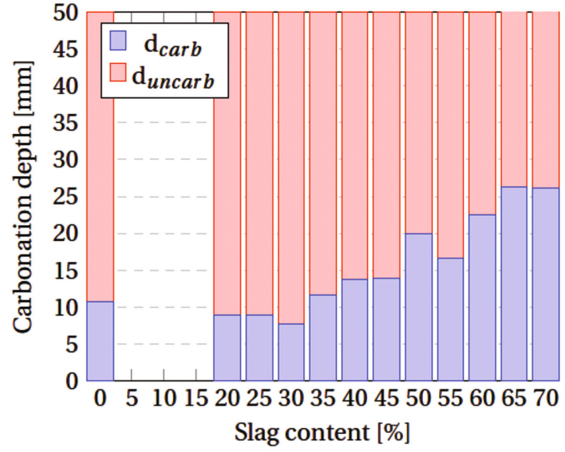

(a)

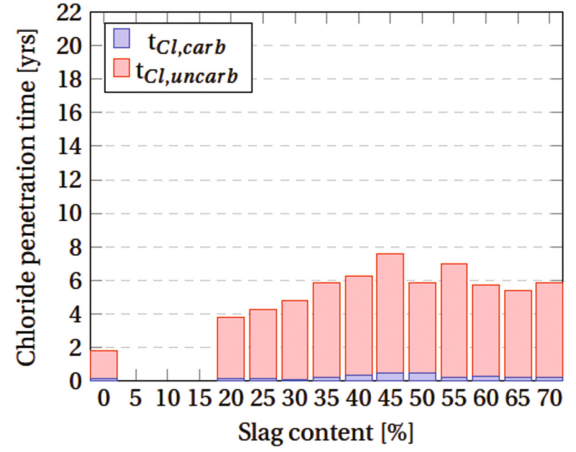

(b)

Fig. 7. 35 years carbonation exposure prior to chloride exposure, (a) Carbonation depth; (b) Time needed for chloride ions to penetrate $50 \mathrm{~mm}$ cover depth after partial carbonation

the same carbonation time by using less slag, for example $45 \%$, a longer penetration time (up to 8 years) can be reached.

\section{Conclusion}

The high chloride penetration resistance of uncarbonated BFSC-mortar with high slag contents is drastically compromised upon carbonation. Mortars containing a high amount of slag, for instance $70 \%$, will also have a significant decrease in electrical resistivity after carbonation. This significant change in resistivity was also observed as a 20 times increase of the $D_{c l}$ after carbonation, which facilitates easy access of chloride ions into BFSC mortars. 
From discussing the Hattemerbroek case study it is concluded that a carbonation period prior to chloride exposure strongly influences the chloride penetration time. The chloride penetration resistance is strongly dependent on the carbonation period and the corresponding carbonation depth. For structural elements that are sheltered and can carbonate longer than 20 years before exposure to chloride a lower slag content than $70 \%$ might be considered, providing a longer chloride penetration time after this carbonation period. Slag contents from $35 \%$ to $50 \%$ should be studied in more detail, as they appear to give a longer chloride penetration time for carbonated material than a $70 \%$ slag binder (CEM III/B).

However, high slag content binders $(>50 \%)$ have more environmental advantages. The model used in this study doesn't take into account a simultaneous coupled effect of carbonation and chloride ingress, which is more realistic case for other exposure conditions than sheltered. The results of this study suggest that instead of only considering a single governing environmental class, i.e. only chloride, combination of exposures should be considered, i.e. carbonation and chloride.

\section{References}

Bertolini, L., Elsener, B., Pedeferri, P., Redaelli, E., Polder, R.B.: Corrosion of Steel in Concrete: Prevention, Diagnosis, Repair. 2nd edn., 414 pp. Wiley-VCH Verlag GmbH \& Co. KGaA, Weinheim (2013). ISBN 3-527-33146-8

Copuroglu, O.: The characterisation, improvement and modelling aspects of frost salt scaling of cement-based materials with a high slag content. Delft University of Technology, TU Delft (2006)

Holthuizen, P.E.: MSc-thesis - Chloride ingress of carbonated slag cement mortars. TU Delft, Delft University of Technology (2016)

Polder, R.B.: Test methods for onsite measurement of resistivity of concrete - a RILEM TC-154 technical recommendation. Constr. Build. Mater. 15, 125-131 (2001)

Polder, R.B., de Rooij, M.R.: Durability of marine concrete structures - field investigations and modelling. HERON 50(3), 133-143 (2005)

Polder, R.B., Peelen, W.H.A., Courage, W.M.G.: Non-traditional assessment and maintenance methods for aging concrete structures - technical and non-technical issues. Mater. Corros. 63 (12), 1147-1153 (2012)

Polder, R.B., Nijland, T., de Rooij, M.R.: Blast furnace slag cement concrete with high slag content (CEM III/B) - Experiences with the durability in The Netherlands since the 1920's. NPRA report SVV 270, 72 pp (2014)

Tuutti, K.: Corrosion of steel in concrete, p. 469. Swedish Cement and Concrete Research Institute, Stockholm (1982)

van der Wegen, G., Polder, R.B., van Breugel, K.: Guideline for service life design of structural concrete - a performance based approach with regard to chloride induced corrosion. HERON 57(3), 153-168 (2012)

NEN-EN-1992-1-1: Eurocode 2: Design of concrete structures - part 1-1: General rules and rules for buildings (2005)

NEN-EN-196-1 (en): Methods of testing cement - Part 1: Determination of strength (2005) 
NEN-EN 206-1 (en): Concrete - Part 1: Specification, performance, production and conformity (2000)

NT Build 492: Concrete, mortar and cement-based repair materials: chloride migration coefficient from non-steady-state migration experiments (1999)

ROK 1.2: Rijkswaterstaat Technisch Document (RTD) - Richtlijn Ontwerpen Kunstwerken. RTD 1001:2013 (2013) 